MORPEOLOGY

OI

THE HBAD = CAPSULE

OI

SOMR COLMOPTWRUS LARVRA 

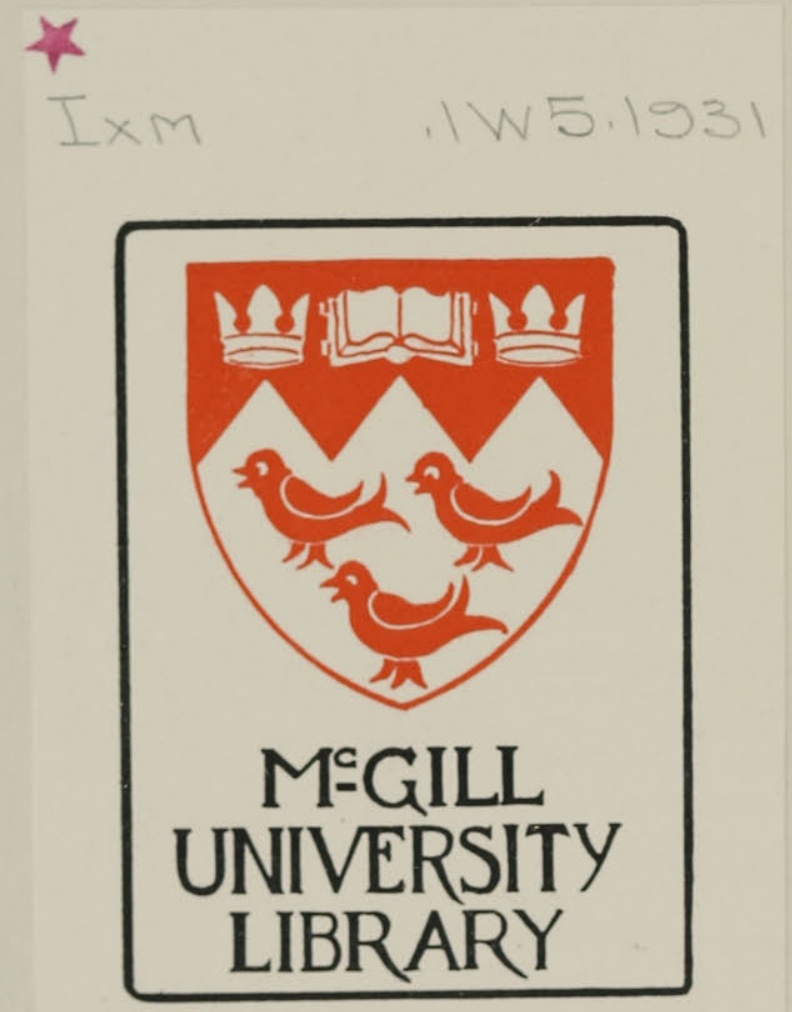

асc. NoLNACC. рате1931 



\section{THE MORPHOLOGY OF THE HEAD-CAPSULE OF}

\section{SONE COIEOPTERUS IIARVAE}

\section{by}

WAITER E. WHITEHEAD

\section{A THES IS}

Submitted to the Faculty of Graduate studies and Research, ncGill University, in partial fulfilment of the requirements for the degree of Master of science. 


\section{TABIE OF CONTENTS}

\section{Page}

Introduction $\ldots \ldots \ldots \ldots \ldots \ldots \ldots \ldots$

Iist of species ................ 3

Acknowledgments .................. 4

Parts of the Head-Capsule .......... 5

ocelli $\ldots \ldots \ldots \ldots \ldots \ldots \ldots \ldots . . . \ldots \ldots$

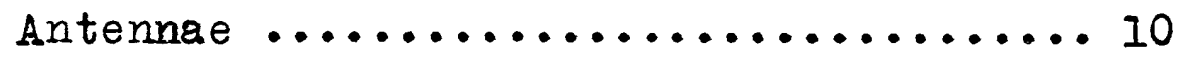

Fronto-clypeal Region ................. II

Postero-ventral Region .............. 18

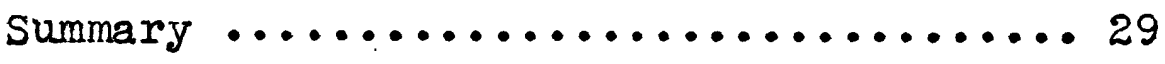

Bibliography ..........................

Abbreviations Used in Labelling Figures 34 


\section{INTRODUCTION}

The original idea of attempting this study was for the purpose of obtaining some data on the phylogeny of the heads of coleopterous larvae. This has not been very successful owing to some difficulty being experienced in obtaining long series of any genus or family necessary for such a study. For this reason the subject is discussed from a comparative standpoint. The order Coleoptera being very extensive and showing a great diversity of form, makes it impossible to cover more than a very small portion in the time available. There are but thirty families represented in the following pages, but these show what diverse conditions obtain in the head-capsules of the larvae.

Both campodeiform and eruciform larvae occur in the Coleoptera. The former is a term taken from Campodea, a genus in the order Thysanura, which represents an early stage in the phylogenetic development of insects and is the more primitive type. Individuals in this group are usually quite active, with horizontal mouth parts and elongate, flattened bodies. The eruciform larvae on the other hand are not so active, the mouth parts are vertical and the body is more or less cylindrical. The form is usually correlated with the insect's habits. Campodeiform larvae are mostly predaceous, which accounts for their activity and great development of the mandibles, whereas the eruciform larvae are usually surrounded by an abundance of food from the time they hatch from the eggs, so that very little activity is necessary. There are also modifications of the 
eruciform type as in the scarabaeid larvae, which develop very heary bodies and show still less activity. In addition to these there are the apodous larvae found among the boring beetles, and in this case there is no need of much movement. Although the campodeiform larvae are the most primitive from an evolutionary standpoint, they show the greatest specialization as far as the sclerites of the head-capsules are concerned. These structures in the eruciform group are of a very much more generalized nature. Whatever the degree of specialization may be however, it bears no relation to the condition found in the adult insects, but is an adaptation dependant upon the requirements of the insects during their larval life. There has been no large amount of work done on the comparative anatomy of coleopterous larvae. With few exceptions, the available literature deals with conditions existing within a family, or even a smaller group, among the most comprehensive of which are probably the work of Gage (8) "Larvae of the Coccinellidae" and that of Hayes (II) "Morphology, Taxonomy and Biology of Larval Scarabaeoidea".

The following discussion, although on a very small scale, will at least give some idea of the wide variation in structure that exists among the larvae in the more common families of the Coleoptera. 


\section{IIST OF SPECIES.}

The following were the available species. They are not arranged in any particular order and the numbers are only given for convenience.

1. Harpalus honestus

2. Carabus nemoralis

3. Cicindela sp.

4. Dytiscus sp.

5. Hydrophilus obtusatus

6. Pseudophonus pubescens

7. Cantharis sp.

8. Gnathocerus punctulatus

9. Cercyon sp.

10. Silvanus surinamensis

11. Epilachna borealis

12. Adalia bipunctata

13. Passalus cornutus

14. Dorcus parellelepipedes

15. Staphylinus sp.

16. Micromalthus debilis

17. Aulonium sp.

18. Synchita $\mathrm{sp}$.

19. Silpha tristis

20. Scaphidium 4-maculatum

21. Thanasinus formicarius

22. Dermestes Iardarius

23. Tenebrio molitor
Carabidae

Cicindelidae

Dytiscidae

Hydrophilidae

Erotylidae

Cantharidae

Histeridae

Sphaeridae

Cucujidae

Coccinellidae

$n$

Iucanidae

"

Staphylinidae

Iymexylonidae

Colydiidae

$n$

Silphidae

Scaphidiidae

Cleridae

Dermestidae

Tenebrionidae 
24. Rhyncophorus cruentatus

Curculionidae

25. Anthonomus grandis

$n$

26. Balaninus $\mathrm{sp}$.

n

27. Osmoderma scabia

Scarabaeidae

28. Allorhina nitida

$n$

29. Phyllophaga anxia

30. Labidomera clavicollis

Chrysomelidae

31. Phyllotreta armorica

32. Chelymorpha argus

33. Leptinotarsa decemlineata

34. Cassida vittata

35. Malachius bipustulatus

Melyridae

36. Anisandrus pyri

Scolytidae

37. Denaroctonus valens

n

38. Orchesia micans

Melandryidae

39. Scobicla declivis

Bostrichidae

40. Chrysobothris femorata

Buprestidae

41. Anthocinus obsoletus

42. Xylotrechus colonus

Cerambycidae

43. Prionis laticollis

44. Saperda candida

45. Lampyris sp.

Lampyridae

46. Agriotes mancus

Elateridae

\section{ACKNOWLEDGMENTS}

To Dr. E. lielville DuPorte, under whose supervision this study has been conducted, I wish to express my appreciation for his instruction and for his criticisms and suggestions during the course of this work. 
I also wish to thank Dr. G.W. Underhill of the Virginia Agricultural Experimental station, for providing me with specimens of Epilachna borealis, Dr. A.W. Rymer Roberts of the Molteno Institute, for representatives of the families Staphylinidae and Cantharidae, and Dr. C.W. Collins of the U.S. Bureau of Entomology, for specimens in the genera Calosoma and Carabus.

\section{PARTS OF THE HEAD-CAPSULE}

Under this heading are included those parts other than the fronto-clypeal and the postero-ventral regions which are dealt with separately.

The accompanying diagrams illustrate the generalized structure of an insect's head. The chitinous walls of the head-capsule constitute the epicranium and this is divided into various sclerites by means of sutures. The vertex is marked by a median coronal suture that turns downward and divides into the frontal sutures which extend to the anterior articulations of the mandibles. The coronal suture and the frontal sutures constitute the epicranial suture. The median facial region between the frontal sutures is the frons, ventral to which, and separated from it by the epistomal suture, is the clypeus, with the labrum suspended from the lower margin of the latter.

A large portion of the posterior surface of the epicranium is occupied by the occipital foramen. Surrounding this opening dorsally and laterally is the occipital area, the anterfor limit of which is defined by the occipital suture. Another suture, the postoccipital, separates the narrow, marginal postocciput to which the cervical membrane is attached. 
The dorsal part of the occipital area anterior to the postoccipit, is termed the occipit and the latero-ventral parts, the postgenae. To the ventral margin of the occipital foramen is attached the labium.

The lateral areas of the epicranium between the occipital suture and the frontal sutures, and separated dorsally by the coronal suture, are termed the parietals. The parietal area behind and below the compound eye is the gena, that between the eyes is the vertex.

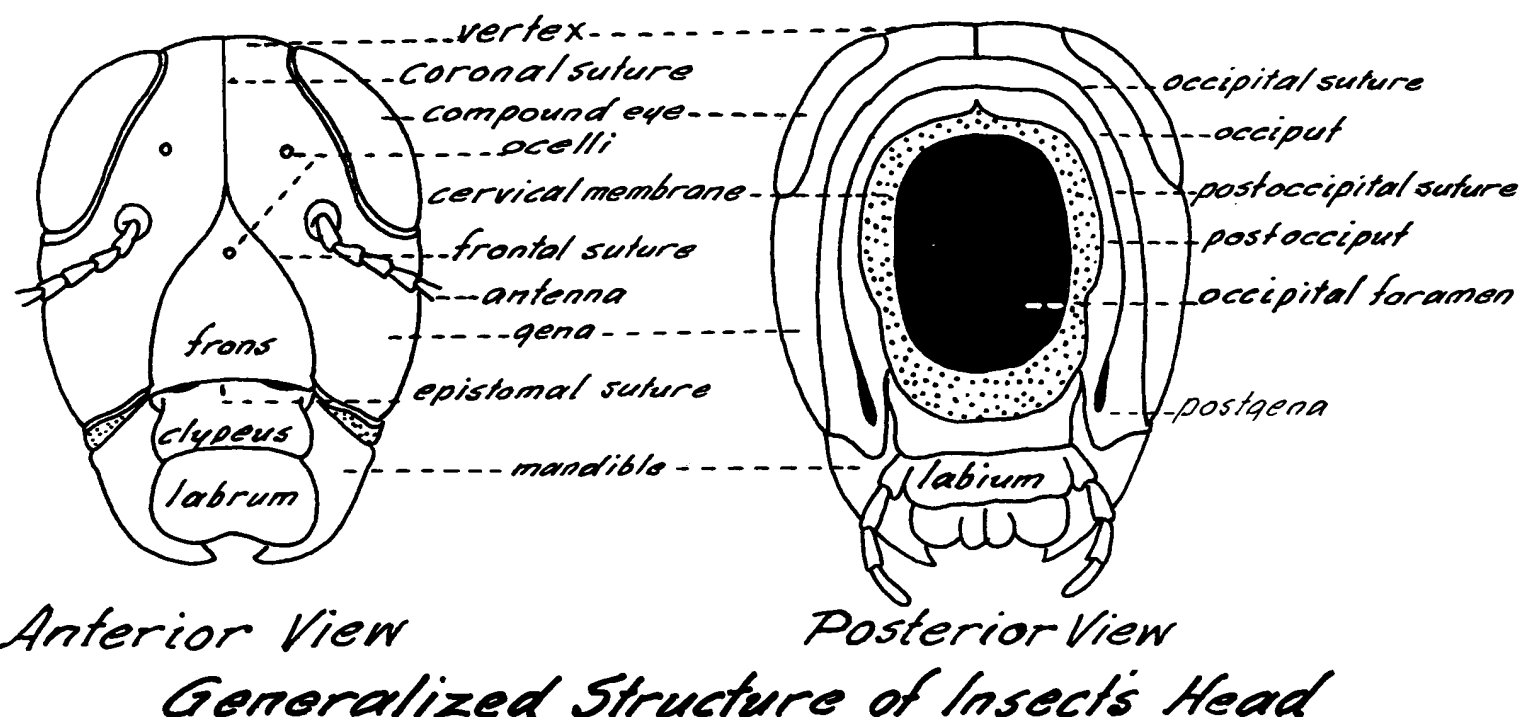


In all the more generalized species of larvae studied there is nothing peculiar about the head, it is held more or less vertically with the occipital foramen located posteriorly. As specialization develops, however, we find this condition changed in many groups, the head becomes uptilted so that it is held in a horizontal position with distinct dorso-ventral compression in many species and invariably a change in the position of the occipital foramen. There is no connection between this specialization and that found in adult Coleoptera, in fact a complete reverse condition often exists, as in the case of adephagous beetles, which are considered to be among the most generalized and which have some of the most specialized structures in the larvae. Many of the polyphagous beetles show quite primitive structures in the larval stages.

It will not be necessary to mention many of the species used, as a similar condition exists in all of them, suffice to say that it is to be noted that in such species as Dorcus (Fig. 3) and osmoderma (Fig. 8) to name only two, we find a generalized condition present. Among other head-capsules of this type there are a few characteristics which might be mentioned. In Rhyncophorus (Fig. 2) for instance, the parietals are crossed by accessory sutures, and in Pseudophonus (Fig. $27 \& 27 \mathrm{~A}$ ) and Hydrophilus (Fig. 30) there are lateral sutures, neither of which appear to be of any structural importance, although they are the only species among those used in this study which show these characteristics. The posterior margin of the dorsum in Phyllotreta (Fig. 20) and Chelymorpha (Fig. 23) are deeply notched, while the latter bears on each dorso-lateral margin 
a group of four tubercles, a characteristic of certain other larvae.

The retraction of the head-capsule within the cervical membrane is a point of interest and shows different degress of development in the series. According to snodgrass (17), the postoccipital ridge in some larvae develops into an apodemal plate, shown in Phyllophaga (Fig. 45) and which is mostly covered by the cervical membrane. This condition is also shown in Dorcus (Fig. 47), Allorhina (Fig. 48), Osmoderma (Fig. 52), and, to a lesser degree, in Rhyncophorus (Fig. 46).

In another group consisting of Chrysobothris (Fig. 12), Scobicia (Fig. 13), Acanthocinus (Fig. 16) Xylotrechus (Fig. 9), Prionis (Fig. 15) and Saperda (Fig. 11), it is to be noted that the head-capsule is deeply retracted within the cervical membrane, To consider that this enveloped condition of the posterior part of the head is a development of the apodemal plate would seem to be an erroneous conclusion. A more probable explanation would be that it is a further development of that found in Phyllophaga where the cervical membrane only covers a comparatively small portion of the postero-ventral surface. As the head assumed a horizontal position, instead of the cervical membrane covering the apodemal plate, gradually receding to the edge of the occipital foramen, it remained stationary, and the dorsal and lateral surfaces of the posterior part of the head-capsule during the course of the uptilting, gradually retracted backward into the cervical membrane. This would also account for the occipital foramen being in ventral position, with the exception of Chrysobothris, in which species it is directly posterior, but cutting 
into both dorsal and ventral surfaces.

There seems to be little doubt that the retracted portion of the head-capsule, or at least a large portion of it, was originally exposed. The sclerotization of both areas is similar, and sutures in some species found on the exposed portion can be distinctly traced backward on to the retracted area. Examples of this condition may be seen in scobicia where there is apparently a distinct coronal suture, also in saperda where wé find a faint continuation of the coronal suture and a distinct prolongation of the lateral sutures.

of those species other than those already referred to, whose head has attained the horizontal position, little more can be said, other than in Hydrophilus (Fig. 30) and Cicindela (Fig. 36) examples of a dorsal occipital foramen occur.

\section{OCELII}

ocelli may be present or absent, they may vary in number from one pair to six pairs (Hydrophilus Fig. 30), there is a wide range in size and their location varies to some extent. They are usually located on the dorso-lateral margin of the parietals near the base of the antennae, although this is not always true, as in Cicindela (Fig. 36), where they are placed considerably posterior to the antennae. As a rule they are easily discernible, sometimes attaining a comparatively large size, as in Dytiscus (Fig. 33) and Cicindela, but may also be quite minute, as in Scaphidium (Fig. 31).

Where more than one pair are present, their grouping is used to some extent in the classification of the larvae. They 
may be close together and evenly spaced as in staphylinus (Fig. 4I) and Harpalus (Fig. 32), or they may be separated into groups, a characteristic in Scaphidium and Labidomera (Fig. 7), or again, they may be close together and all arranged on a prominence as shown in Carabus (Fig. 34).

It is among the boring larvae and those that have a subterranean habitat, that we find the forms having no ocelli.

\section{ANTENNAE}

As in other characters, the antennae exhibit much variation. They are located in the cephalo-lateral area of the headcapsule, the frontal sutures, when complete, invariably extending to their bases. There is some departure from the ir usual location in Cercyon (Fig. 44), Staphylinus (Fig. 4I) and Hydrophilus (Fig. 30), where they have migrated medially. There is also some variation as to their proximity to the bases of the mandibles. In such examples as Silpha (Fig. 28), Adalia (Fig.39), Thanasinus (Fig. 26), Tenebrio (Fig. 19), Harpalus (Fig. 32) and Pseudophonus (Fig. 27), the antennae are situated close to the mandibular articulations, but Leptinotarsa (Fig. 10) and Cassida (Fig. 43) show them to be situated posterior to the mandibular joints.

Mrachius (Fig. 17) shows a unique condition as far as this series is concerned. The antennae are situated in cavities and are probably protrusible, although this point could not be ascertained with the material available.

Size show a very wide range. In boring larvae such as Anthonomus (Fig. 21), Anisandrus (Fig. 35) and Chrysobothris 
(Fig. 12) to mention only three, the antennae are minute, and from these there is a gradual increase in size to those found in Silpha (Fig. 28). Not only is the difference in length, but there is also a marked difference in diameter, as illustrated when comparing Silpha with Scaphidium (Fig. 31). There is usually a basal process, well illustrated in Passalus (Fig. 14) and the segments attached to that and which are numbered from the base, may be conical as in Chelymorpha (Fig. 23A) and the boring larvae, globular in Passalus, or elongate as in staphylinus (Fig. 41), Silpha, or Dorcus (Fig. 3).

A supplemental process occurs on some antennae, the location of which also varies. In Micromalthus (Fig. 24) it is found on the first segment, in Cercyon (Fig. 44), Agriotes (Fig. 29) and Aulonium (Fig. 40) on the second, while the third antennal segments bear them in Staphylinus, Harpalus (Fig. 32) and Pseudophonus (Fig. 27).

The only species which has apparently no antennae is Rhyncophorus (Fig. 2) and although a careful examination has been made, it has failed to reveal any. The antennae are very inconspicuous in the other boring larvae but in this species have disappeared altogether.

\section{FRONTO-CLYPEAL REGION}

The fronto-clypeal region includes, typically, the front or frons, that area between the frontal sutures, which extend from the coronal suture to the neighbourhood of the anterior articulations of the mandibles, and the clypeus, that area ventrad, or cephalad, depending on the angle of the head, to 
the front. This area is separated from the front by the epistomal suture, a groove coinciding with an internal transverse ridge between the anterior articulations of the mandibles and which strengthens the lower edge of the face. It has been suggested by some writers that the clypeus was an articular region between the front and the labrum and which secondarily developed into a sclerotized plate. snodgrass (17) however, disproves this by the fact that the most anterior muscles of the stomodeum have their origin upon the inner surface. The clypeus often shows some differentiation in being divided by a partial or complete suture into an anteclypeus, a more or less membranous area next to the labrum, and a postclypeus adjacent to the front.

For convenience it might be well to mention the labrum at this time, as where modifications occur in the fronto-clypeal region, this area is frequently involved. The labrum, unlike the two preceding parts, is movable, hangs as a free flap before the mouth and is attached to the anterior margin of the clypeus.

of the head-capsules under consideration, a typical frontoclypeal area is singularly well illustrated in Phyllophaga (Fig.l) a species, which as $f a r$ as this region is concerned, shows a very generalized condition, and on which all the aforementioned points may be observed. While several other species are as typical, it might be well to use this one as a standard by which the various modifications occurring in other species may be compared.

In order to facilitate analysis those species showing similarities will be grouped together as much as possible. The first group includes Dendroctonus (Fig. 25), Anthonomus (Fig. 21), 
Thanasimus (Fig. 26), Osmoderma (Fig. 8), Orchesia (Fig. 5), Tenebrio (Fig. 19), Phyllotreta (Fig. 20A), Labidomera (Fig. 7), Dorcus (Fig. 3), Balaninus (Fig. 6), Rhyncophorus (Fig. 2), and Malachius (Fig. 17). All of these species have a full complement of parts in the region under discussion and it will be found that the frontal sutures are fully developed. Osmoderma, Tenebrio and Dermestes are very similar to Phyllophaga, but certain slight modifications occur in some of the other species. These are concerned with the coronal suture which extends beyond the union of the frontal sutures on to the front for varying distances. In Dorcus it is quite short, somewhat longer in Balaninus, Anthonomus and Dendroctonus, while in Phyllotreta and Labidomera it extends to the epistomal suture. The clypeus is very suppressed in Malachinus, but is intact. The second grouping consists of Silvanus (Fig. 18), Epilachna (Fig. 22), Leptinotarsa (Fig. 10), Passalus (Fig. 14), Allorhina (Fig. 4), and Chelymorpha (Fig. 23A). In these species too, are to be found all the parts of a typical fronto-clypeal region, but the frontal sutures are incomplete. Passalus, Epilachna and Leptinotarsa show distinct but shortened sutures; in silvanus and Allorhina, they are becoming indistinct, while in Chelymorpha they are only vestigial. In Chelymorpha too, it is to be noted that the frontal sutures originate at the posterior margin of the head and the coronal suture extends to the epistomal suture, the latter modification also being applicable to Leptinotarsa - In Epilachna, Underhill (19) figures what is apparently a double coronal suture and the frontal sutures closely converging near their distal extremities, all of which are indicated as being quite indefinite. He also shows a double epistomal suture. 
Gage (8) does not find this condition existing in the coronal suture or in the epistomal region, neither were they observed in the specimens examined by the writer.

Another group consists of Scaphidium (Fig. 3I), Silpha (Fig. 28), Casside (Fig. 43), Anisandrus (Fig. 35), Micromalthus (Fig. 24), Aulonium (Fig. 40) and Adalia (Fig. 39), because they each show a tendency towards reduction in sutures, or because there is an apparent complete disappearance of some part as compared with the primitive type. of these, scaphidium is the only one having complete frontal sutures, those in Adalia are almost so and those in Aulonium, which is minus a coronal suture, show somewha-t less development, while they are only vestigial in Silpha. In Anisandrus the sutures have disappeared, leaving only the coronal suture, in which case frons and parietals combine to form the fronto-parietals. A similar condition exists in Micromal thus and Cassida, but in these, the coronal suture extends to the epistomal suture. Such a condition may be the result of the forward migration of the frontal sutures, but this would not hold with the views of Barber (I) as far as the larval Micromalthus is concerned, as he believes this species to have a distinct clypeus, in which case the dividing suture would be the epistomal.

Apart from these modifications of the epicranial suture, all the foregoing species with the exception of Cassida, show that there is a tendency for the epistomal suture to disappear. The suture in Anisandrus can be followed throughout its course, but in the remaining four species it has entirely disappeared with the exception of the lateral portions. 
Some of the wood-boring larvae show certain modfications and the following representatives are grouped togethe $r$ on account of the nature of the head-capsule. Saperda (Fig. II) Prionis (Fig. 15), Xylotrechus (Fig. 9), Anthocinus (Fig. 16), Chrysobothris (Fig. 12) and Scobicia (Fig. 13).

The retraction of the head-capsule into the cervical membrane may have some bearing on the structure of the frontoclypeal region, as the distance between the margin of the membrane and the anterior extremity of the head becomes considerably shortened. Saperda and Chrysobothris are perhaps nearest to the typical condition as far as the frontal sutures are concerned, they are not complete in either of the species, but they are at least definitely show. The coronal suture in each instance extends throughout the length of the front. In Anthocinus the frontal sutures have almost disappeared and in the remaining species they have done so entirely. The coronal suture persists in Prionis, is very reduced in Xylotrechus and has completely gone in Scobicia.

The epistomal sutures are intact in all species except in Scobicia and here the median portion is missing. It is to be noted that there is a reduction of sutures in Chrysobothris, but it is apparently the suture between the labrum and the crypeus that is absent, as from the position of the tentorial pits, the epistomal suture appears to be intact.

The remaining species studied may be divided into two groups, the larger consisting of Hydrophilus (Fig. 30), Cicadela (Fig. 36), Carabus (Fig. 34), Harpalus (Fig. 32), Pseudophonus (Fig. 27), Dytiscus (Fig. 33), Lampyris (Fig. 37), Staphylinus 
(Fig. 41), Agriotes (Fig. 29) and Cantharis (Fig. 38). Hydrophilus perhaps shows the least specialization in the fact that there is at least a slight differentiation between the labrum and the clypeus. Dytiscus too, may also be mentioned in this connection, as while no labrum can be seen from the dorsum, this structure may be observed from a cephaloventral aspect. Staphylinus and Lampyris show a fusion of the labrum and clypeus, but the others, with the exception of Cantharis and Cicadela, each of which have what are evidently vestiges of sutures, there is no differentiation between the front, the clypeus and the labrum. It is to be noted in all species in this group, that the frontal sutures are very well defined and in most instances complete. A major character in Agriotes is that the cephalic margin is tridentate.

The last two species, Gnathocerus (Fig. 42) and Cercyon (Fig. 44) are the most specialized of all, the epicranium being entirely devoid of sutures. Cercyon bears two notches on the anterior margin which are probably the remains of some previous suture, and Gnathocerus has an extended area at the cephalic margin, which is also notched to a lesser degree, but there are no sutures apparent to differentiate the parts.

From the foregoing discussion it will be obvious that there is a very wide variation of structure in the fronto-clypeal region, ranging from a simple, generalized condition in Phyllophage, to a highly specialized structure as found in such species as Cercyon and Gnathocerus.

In his mork with the head-capsules of adult Coleoptera, Stickney (18) found that in the majority of species, the development trends towards the obliteration of sutures, consequently 
giving greater compactness and consolidation of sclerites and with a tendency towards stronger sclerotization of the headcapsule. This is 311 quite applicable to the head-capsules of the larvae. In the eruciform and melolonthoid forms, we have species showing the least amount of sclerotization, but the most complete conditions from a primitive standpoint. At the same time the obliteration of sutures has begun in the disappearance of part, or all of the frontal sutures, resulting in a fronto-parietal region, as well as at least the partial disappearance of the epistomal suture, leading towards the formation of a fronto-clypeus.

Among the campodeiform larvae is to be found a gradual increase in specialization, culminating in a complete consolidation of parts. Such species as Hydrophilus are probably the most generalized of this group, but they are more highly specialized than the eruciform species, while the other species in the group show a gradual tendency towards the obliteration of sutures. With this obliteration, comes a much greater degree of sclerotization, the cephalic margin of the most highly specialized forms being very marked in this respect. No doubt the habits of the larvae have something to do with the amount of sclerotization they possess, although it seems natural that as the sutures disappear, there should be a tendency towards the strengthening of those areas. The degree of disappearance of sutures seems to coincide with the degree of sclerotization, as illustrated in the clypeo-labral area. 


\section{POSTERO-VENTRAL REGION}

If all parts of the postero-ventral region of the headcapsule are to be mentioned, they would include the labrum, the maxillae, the postgenae, the occiput, the postocciput, and, in some species, the gula. The mandibles also have a ventral, or posterior articulation and are frequently observed from this aspect.

The labium consists of a basal part, the submentum, anterior to which is the mentum to which is attached the eulabium, or what Crampton terms the prementum, which bears the palpi. In the more generalized insects, the labium hinges to the posterior margin of the head, completing the ventral margin of the occipital foramen, and on either side of it are to be found the proximal parts of the maxillae, and, depending on the nature of the occipital foramen, the anterior median portions of the postgenae.

The maxillae are complicated gnathal appendages situated in the membrane on either side of the labium.

The postocciput is a narrow sclerite surrounding the occipital foramen and the postoccipital suture, which separates it from the occiput, is an important landmark of the head. It is usually present and the posterior tentorial pits are located in its lower ends; if the pits migrate, the lower ends of the suture become correspondingly longer.

The foregoing parts are shown in Dorcus (Fig. 47). In generalized insects the heads are held vertically, in which case the posterior part of the head is naturally rather short, and while modifications do occur, they are not as profound as in insects possessing a gular region. 
A fully developed gula is chiefly found in those insects whose head is held horizontally, and not always then, and as this condition develops, there is a lengthening of the posteroventral part of the head, the labium moving forward, thus causing the area between the occipital foramen and the submentum to become very much greater.

The origin of the gula has long been a controversial subject. Crampton (7) and later Snodgrass (I7) have, however, advanced a theory which seems to be generally accepted, a madified account of which is briefly given here by way of partly explaining, the modifications that occur.

In some larvae, Phyllophaga (Fig. 45) would be an example of those under discussion, the face is directed forward, the mouth parts hang downward and the under surface of the head is short. The occipital and postgenal regions terminate in a postoccipital suture, in the ventral ends of which are situated the invaginations of the posterior arms of the tentorium. Beyond the suture is a narrow postoccipital rim of the cranium, best developed ventrally and the postoccipital ridge is developed on each side of the occipital foramen into an apodemal plate, the two uniting ventrally into the tentorial bridge. The basal part of the submentum is sclerotized to form a triangular plate which is attached to the mesal points of the postgenae and has its extreme basal angles prolonged to points behind the tentorial pits.

In Silpha (Fig. 70), the general structure of the head is similar, but it will be observed that the ventral postgenal margins are much longer and the posterior tentorial pits are drawn 
towards the median line in the prolonged basal angles of the postgenae. The base of the submentum is narrowly constricted between the tentorial pits, which almost cut off a distinct proximal area, the lateral angles of which become continuous with the postoccipital rim.

The extreme basal area of the submentum is the beginning of the gula which reaches various degrees of development in different species. It is that area between the posterior margin of the submentum and the occipital foramen, the distal extremity of which may be designated as the pregula. Externally, the gula may be marked off anteriorly by the tentorial pits (gular pits), although Crampton has adrocated that a line drawn from the basal articulation of one cardo to the other might be preferable to using such shifting landmarks as the gular pits. With the uptilting of the head and the necessary elongation of the ventral area, the gular pits tend to move forward, under which conditions the gula would become proportionately longer. The gula is bounded laterally by the gula sutures, on or near which are situated the gular pits. On either side of the gula are the postgenae, or what are termed by crampton the paragulae, who also differentiates the anterior portion as being the hypostoma.

Concerning the head-capsules that are to be considered, it is not difficult to divide them into two groups, namely, those that possess a gula and those that do not; it is difficult, however, to make further subdivisions owing to the general similarity that exists among many of the species. An effort will be made to group those of different types together, beginning with those that appear to be the more generalized. 
The species Phyllophaga has already been mentioned in connection with the development of the gular region and there are three other species which resemble this one in respect to the ingrowth of the postoccipital ridge as an apodeme, which is overgrown by the cervical membrane. Phyllophaga and Osmoderma (Fig. 52) are very similar, except that the occipital foramen is much larger in the latter. The apodeme is quite extensive in both and it is strengthened by heavily sclerotized cross-bars. The only other differences appear to be a more complex maxilla in Osmoderma and a submentum that is separated from the mentum by a membranous area. Dorcus (Fig. 47) and Allorhina (Fig. 48) show some similarity in this region and might be placed together, the most noticeable differences being the apparent absence of a postgenal suture in Allorhina and a more extended submentum. occipital apodemes are present in both species. Rhyncophorus (Fig. 46) might also be grouped here as it has some points in common with the others, the ingrown area, however, does not surround the occipital foramen, but only extends over the ventral and part of the lateral margins. An occipital apodeme is present, and the submentum is large, but compared with the surrounding parts of the headcapsule, it is much less heavily sclerotized, the condition belng indicated in the figure by slight stippling. Seren species consisting of Leptinotarsa (Fig. 56), Anthonomus (Fig. 71 ), Balaninus (Fig. 50), Labidomera (Fig. 51), Chelymorpha (Fig. 62) and Malachius (Fig. 63) may be grouped together in that they have one characteristic in common, that is, the postgenae have grown together forming a bridge of varying 
widths between the occipital foramen and the submentum, and this, together with the tentorial bar, which may be found fused to part of the ental surface, forms a heavily sclerotized plate, adding very considerably to the strengthening and bracing of this area of the head-capsule and resembling very closely the condition found in Lepidoptera. This bridge is quite wide in Malachius, Leptinotarsa and Balaninus and is narrowest in Chelymorpha. In all species with the exception of Malachius, the submentum shows great development, at the expense, in most cases, of the basal parts of the maxillae and the mentum, which is greatly reduced. In Malachius the labium and maxillae show a comparative decrease in size and their situation is more caudad, probably due to the fact that the occipital foramen is more posterior in location. This condition causes the labrum, clypeus and even part of the front, to be considerably anterior to the cephalic margin of the labium and maxillae. The mentum and submentum are apparently fused. The postoccipital area is not well developed in most of the foregoing species, the suture being indiscernible in some of them. An occipital apodeme occurs in Balaninus and Anisandrus, the latter also having a frontal apodeme.

Dendroctonus (Fig. 76) might be included here as it somewhat resembles the preceding species. The mentum is well developed, but the submentum, called the submental lobe by Hopkins (12), is partly membranous and is separated from the maxillae and the occipital foramen by a membranous area. The group, whose heads are retracted within the cervical membrane, also have a fusion of the postgenae between 
the occipital foramen and the submentum. In Scobicia (Fig.57) this area is practically all covered by the cervical membrane and in Acanthocinus (Fig. 59) it is partially covered. In Chrysobothris (Fig. 54), Xylotrechus (Fig. 53), Prionis (Fig. 58) and Saperda (Fig. 55) however, it is fully exposed. The mentum and submentum are distinct in all species, and other than the retraction of the head and a ventral occipital foramen, points which have already been discussed, there is nothing characteristic about this group.

Two other species, Phyllotreta (Fig. 64) and Orchesia (Fig. 49) are very similar to the foregoing series, but they lack the postgenal bridge already referred to, which makes the posterior margin of the submentum adjacent to the occipital foramen without any gular development. This is a similar structure to that which one would expect in such species as Phyllophaga and Osmoderma were it not for the development of the postoccipital ridge, the cervical membrane, in the case of the two foregoing species, being attached to the edge of the occipital foramen.

Still two other species, Agriotes (Fig. 73) and Lampyris (Fig. 83) are different from all the others. Agriotes whose head is held horizontally and whose occipital foramen is directly posterior, has a membranous area between the submentum and the occipital formen and between the mos $t$ developed portions of the postgenae. The cardines of the maxillae are small sclerotized areas in the membrane and besides these, are two other isolated areas which Crampton (6) terms the submentales. In addition to these are two other slightly sclerotized areas 
joined to the posterior margin, which might be the remains of a more extensive sclerotized area. The submentum is very elongate, likewise the maxillae and the mentum is quite definite. The second species, Lampyris, is not identical with Agriotes, but it has some resemblance in that it also has a posterior membranous area. A possible explanation of this, however, may be because the head of. this species is retractile within the prothorax, attached to which is a collar, or fold, only slightly sclerotized, which assists in the mechanism of this function. This is not to say that the head could not be retractile if it were heavily sclerotized, but as the posterior part of the head is never exposed, but attached to the collar which also acts as a protection, there is no need of heavy sclerotization. The submentum is elongate, somewhat like that in Agriotes, and while no definite submentales are present, there are a pair of thickenings in the same pdsition as these areas in Agriotes which may correspond to them and which are surrounded by a dotted line in the figure.

It is also possible to separate to some extent, the species of larvae that possess a gula. Silpha (Fig. 70) has al ready been taken up in connection with the development of this region and it will be seen that the gula occupies but a small area, but that the submentum, mentum and prementum are all well developed. In Tenebrio (Fig. 75), Dermestes (Fig. 66), Scaphidium (Fig. 72), Passalus (Fig. 60) and Thanasimus (Fig. 67), the gula is well developed, being very elongate in the last mentioned species, with decided 
evidence of the tendency of posterior ends of the gula sutures to become approximated. Silvanus (Fig. 61) has a distinct gula, but the suture between 1 t and the submentum has started to disappear. This disappearance is complete in Synchita (Fig. 86), Adalia (Fig. 84) and Epllachne (Fig. 69) resulting in the formation of a gulamentum. Gage (8) figures a distinct suture between the gula and submentum in Epilachna, but in the specimens examined, not a vestige of one was visible, neither was the suture separating the submentum from the mentum apparent.

A different condition occurs in Staphylinus (Fig. 82) and Hydrophilus (Fig. 80), the approximation of the posterior parts of the gular sutures, referred to as commencing in Thanasimus, has, in these two species, become complete, forming a single median suture, called by Crampton (7) the epigular suture, who explains this condition as being due to the fact that the gula in this area has become infolded, and he suggests the name of epigulae for those parts of the postgenae which become approximated over it. This area is the more extensive in Hydrophilus, but in each instance the visible portion of the gula is situated anterior to the epigular suture. The labium in each species is normal, but the maxillae are worthy of mention. It will be seen that the stipites are very long, as are the galeae, while the laciniae are very much reduced. Altogether these appendages more nearly resemble antennae than gnathal appendages.

The remaining species are highly specialized and it is difficult to interpret the parts accurately. Cercyon (Fig. 87) and Carabus (Fig. 78) appear to be the most 
generalized of this group and are very similar. The epigular suture extends throughout the length of the ventral surface of the head, with a small pregular area at its anterior extremity, this is membranous in Carabus, which is probably a secondary development, and although the gular sutures are complete in this species, they are beginning to disappear in Cercyon. The mentum and submentum are fused in both species. Cicindela (Fig. 79) probably comes next from a standpoint of specialization. In this species, the pregula has disappeared, but the gular sutures remain definite as far as the gular pits, but are only faintly indicated from that point to the margin of the submentum. In this case the gular sutures have retained their identity, but have practically become fused. Dytiscus (Fig.77) shows still further development in that the anterior portion of the epigular suture has quite disappeared and that portion posterior to the gular pits is very indistinct. This species possesses a well-defined submentum, also a very definite occipital suture. Harpalus (Fig. 75) and Pseudophonus (Fig. 68) show some similarity. The gular sutures are separate in the latter and fused in the former, but while they are definite, they are very much shorter than in the preceding species, which indicates that the gula has been forced out still further, leaving a greater unbroken area in that resion of the ventral surface. There is some development betweer the bases of the maxillae, especially in Harpalus which is possibly the remains of the submentum, al though there is no suture separating it from the postgenae.

The greatest specialization occurs in Cantharis (Fig. 8I) 
and Gnathocerus (Fig. 85), as in these species the re is no indication of any gular sutures, the ventral surface beinf entirely unsegmented. The gular pits were observed in Gnathocerus and a small menbranous area has developed in the postgenae adjacent to the labium, the maxillae are reduced to a minimum, so that the great degree of specialization gives the ventral surface a very simplified appearance. The gnathal appendages in Canthar is show greater development and give a more generalized appearance, but so far as the fixed parts are concerned, there is little difference between the two species.

Any conclusions that may be drawn from the preceding discussion on the postero-ventral region of the head-capsule, must be along the same lines as those given in connection with the fronto-clypeal region, namely, that there is a strong tendency towards the obliteration of sutures and a greater consolidation of parts. It must be borne in mind that there are two distinct types of heads among the species studied, those that have a gula and those that have not. The gradual changes towards specialization, so striking in the former, are not as noticeable in the latter, so far as the postero-ventral region is concerned, as the occipital foramen, in many species, occupies a large area, and the fact that the head is generally shorter, does not allow or require much modification. There are, of course, exceptions to this, but as a general rule, the greatest modifications occur where a gula is developing, or where one is disappearing. 
It is interesting to note how the gula is believed to develop and then to follow its gradual disappearance, which is fairly completely illustrated in this paper, beginning with a fully developed gula and the gradual drawing together of the gular sutures until they finally meet in an epigular suture, first at the posterior margin and later throughout the entire length of the ventral surface, until the gula has been forced out. Following this, the suture gradually disappears, resulting in the fusion of the postgenae into one solid piece covering the entire ventral surface of the head-capsule. The sclerotization is not as heavy on the ventral surface as it is on the dorsal, but as the sutures dis appear, there is naturally a greater compactness, and this, in most cases, corresponds in the different species, to the modifications that are at the same time occurring in the fronto-clypeal area. In some insects, it is believed that certain sclerites force their way in between the base of the labium and the cervical membrane which later develops into the grala. The theory with regard to its formation in the Lepidoptera and Hymenoptera, is that the inner angles of the postgenae become separated off, fuse and form the gula. This theory is the one advanced by Stickney (18) with regard to the development of this area in the Coleoptera. He believes that it is formed by the migration of the invaginations of the posterior arms of the tentorium from the occipital foramen towards the submentum, and must therefore be derived from the postgenae. In this migration, sutures are produced which are the gular sutures, between which is the gula. 
The view which snodgrass (I7) takes, however, and which has already been referred to, namely, that the gula originates from the submentum, is more recent and the one which finds most favour at the present time.

\section{SUMMARY}

1. Only a limited amount of work has been done on the comparative anatomy of the head-capsules of coleopterous larvae.

2. A very wide variation of structure occurs among the species studied.

3. Th1s variation ranges from a very generalized condition in such species as Phyllophaga, to a condition showing great specialization, as in the genus Gnathocerus and others. Whatever the degree of specialization, however, there is no relation between it and the condition found in the adults.

4. Antennae were present in all species with the exception of Rhyncophorus. They were comparatively long and conspicuous in some species and very minute in others.

5. Ocelli may be present or absent and differ both in number and position.

6. As a general rule, the more generalized condition was found among the eruciform type of larvae.

7. Among the campodeiform species the greatest specialization occurs. This is, in some measure, due to the fact that the head is held in a more or less horizontal pasition. 
8. The general trend of specialization is towards the obliteration of sutures and a greater compactness and consolidation of the head-capsule.

9. Coincident with the loss of sutures, there is a tendency towards greater sclerotization.

10. While other conditions undoubtedly occur among species that have not been studied, they would come within the two extremes of structure found among the species dealt with in this paper. 


\section{BIBIIOGRAPHY}

1. Barber, H.S.

1913. Observations on the Life-History of Micromalthus debilis. Proc. Ent. Soc. Wash. XV, pp. 3I-37.

2. Boving, A.G.

1920. Larvae of North American Beetles of the Family Cleridae. Proc. U.S. Nat. Hus. IVII, pp. 575-649.

3. Boving, A.G.

1922. Description of Larvae of Bostrichidae and of Scobicia declivis. U.S. Dept. of Agr. Bul. 1107, pp. 49-54 appendix.

4. Cotton, R.T. \& St. George, R.A.

1929. The Meal Worms. U.S. Dept. Agr. Tech. Bul. 95.

5. Craighead, F.C.

1920. Biology of some Coleoptera of the Families Colydidae and Bothrideridae. Proc. Ent. Soc. Wash. XXII, pp. I-I3.

6. Crampton, G.C.

1921. The Sclerites of the Head, and the Mouthparts of Certain Immature and Adult Insects. Ann. Ent. Soc. Am. XIV, pp. 65-110.

7. Crampton, G.C.

1928. The Eulabium, Mentum, Submentum and Gular Region in Insects. Jour. Ent. \& Z001. 21, 1-15.

8. Gage, J.H.

1920. Larvae of the Coccinellidae. Ill. Biol. Monog. VI. 
9. Hamilton, Clyde $C$.

1925. Studies on the Horphology, Taxonomy and Ecology of the Larvae of Holarctic Tiger-Beetles (Family Cicindelidae). Proc. U.S. Nat. Mus. 65, Art. $17 \cdot$

10. Hayes, $\mathrm{Wm} \cdot \mathrm{P}$.

1928. The Epipharynx of Lamellicorn Larvae (Coleop.), wi th a Key to Common Genera. Ann. Ent. Soc. Am. 21, 282-306.

11. Hayes, Wm. P.

1929. Morphology, Taxonomy and Blology of Larval Scarabaeoidea. III. Biol. Honog. XII, No. 2 .

12. Hopkins, A.D.

1909. The Genus Dendroctonus (Scolytidae). U.S. Dept. Agr. Bur. Ent. Tech. Ser. BuI. 17, Pt. I.

13. Hyslop, J.A.

1917. The Phylogeny of the Elateridae Based on Larval Characters. Ann. Ent. Soc. Am. X, pp. 233-263.

14. Richmond, E.A.

1920. Studies on the Biology of the Aquatic Hydrophilidae. Am. Mus. Nat. H1st. BuI. VoI. XIII, Art. I, pp. 1-94.

15. Roberts, A.W. Rymer

1930. A Key to the Principal Families of Coleoptera in the Larval Stage. Bul. Ent. Res. XXI, pp. 57-72.

16. St. George, R.A.

1925. Studies on the Larvae of North American Beetles of the Subfamily Tenebrioninae with a Description of the Larva and Pupa of Merinus laevis (Olivier). 'Proc. U.S. Nat. Mus. 65, Art. I. 
17. Snodgrass, R.E.

1928. Morphology and Evolution of the Insect Head and its Appendages. Smithsonian Misc. Coll. IXXXI, No. 3 .

18. Stickney, F.S.

1923. The Head-Capsule of Coleoptera. III. Biol. Monog. VIII, No. I.

19. Unđerhil1, G.W.

1923. The Squash Iady-Bird Beetle. Va. Agr. Exp. Sta. Bul • 232. 
ABBREVIATIONS USED IN IABELLING FIGURES.

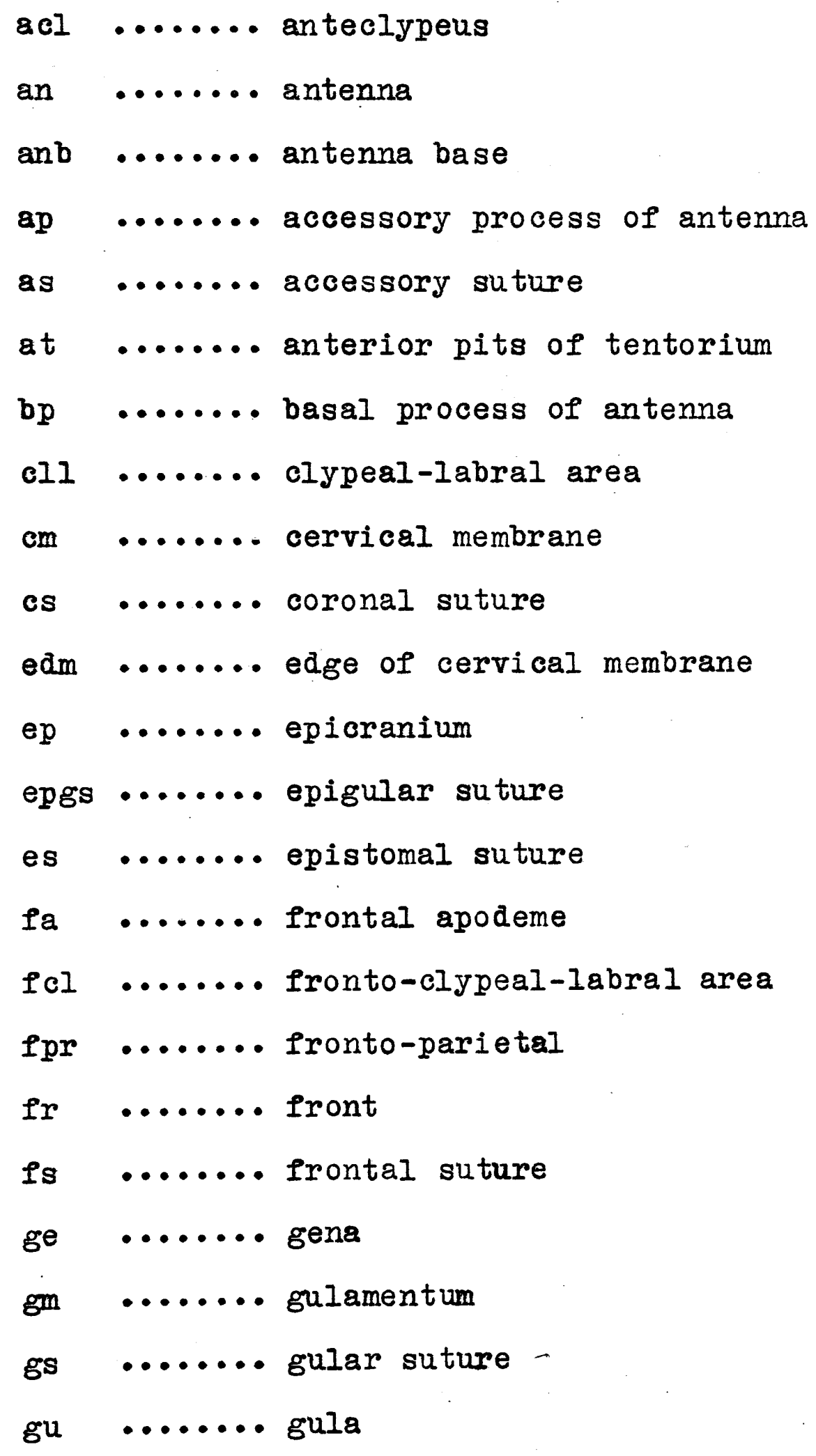




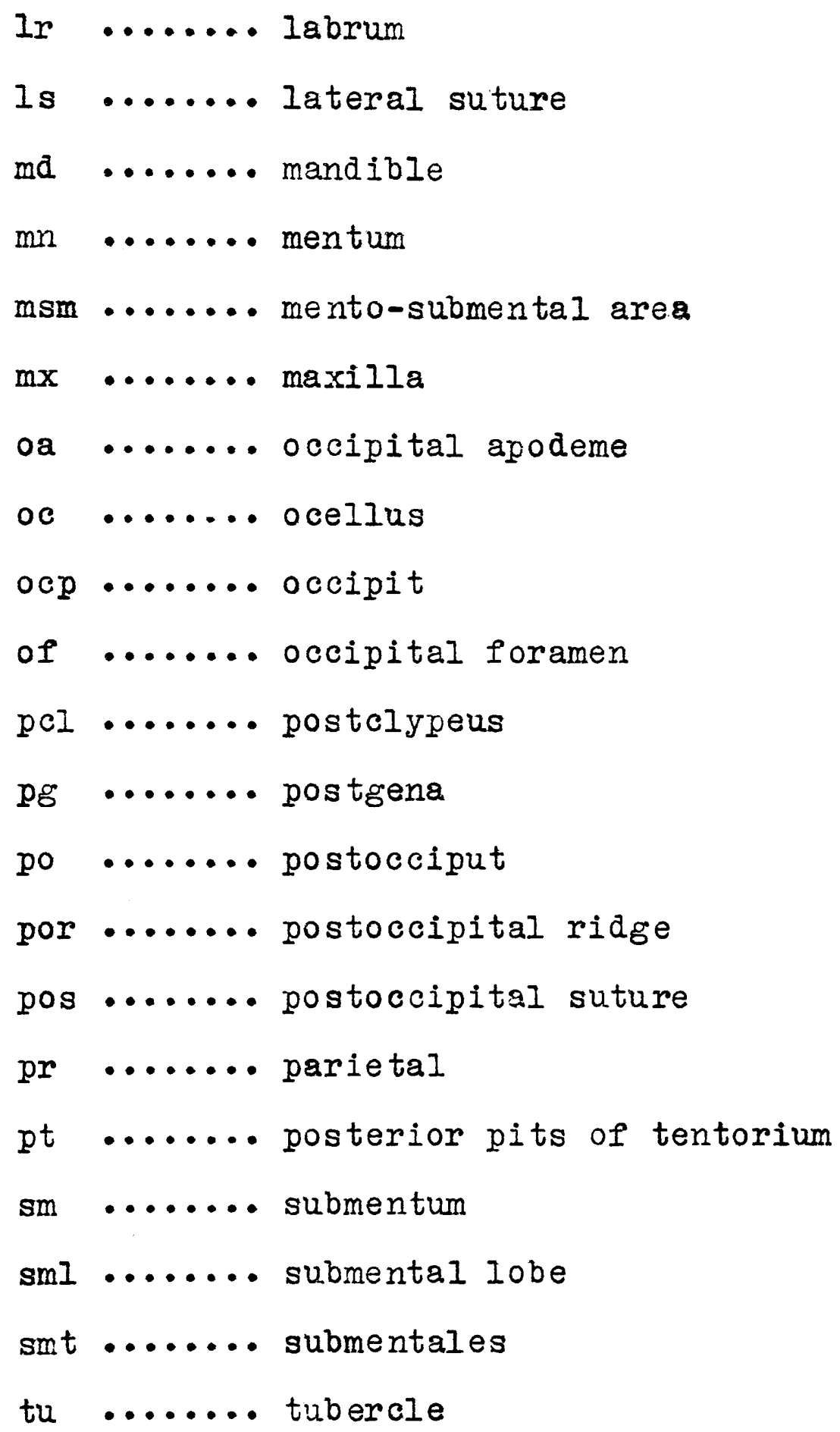




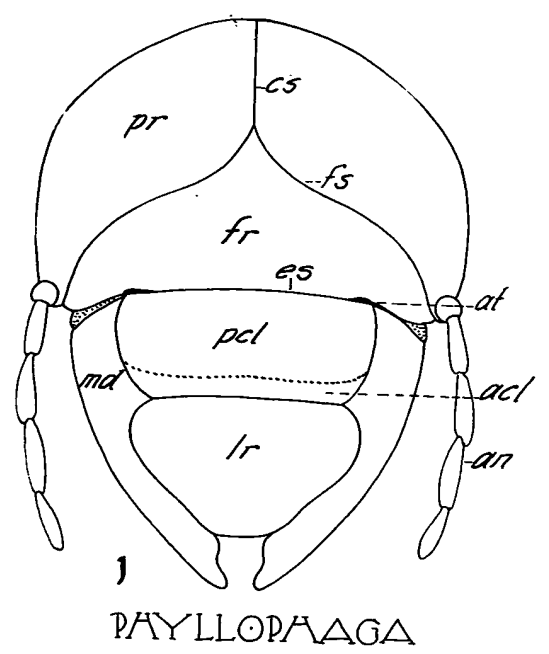

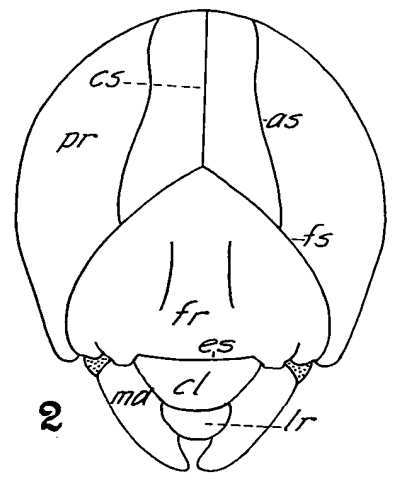

RAYNCODAORUS
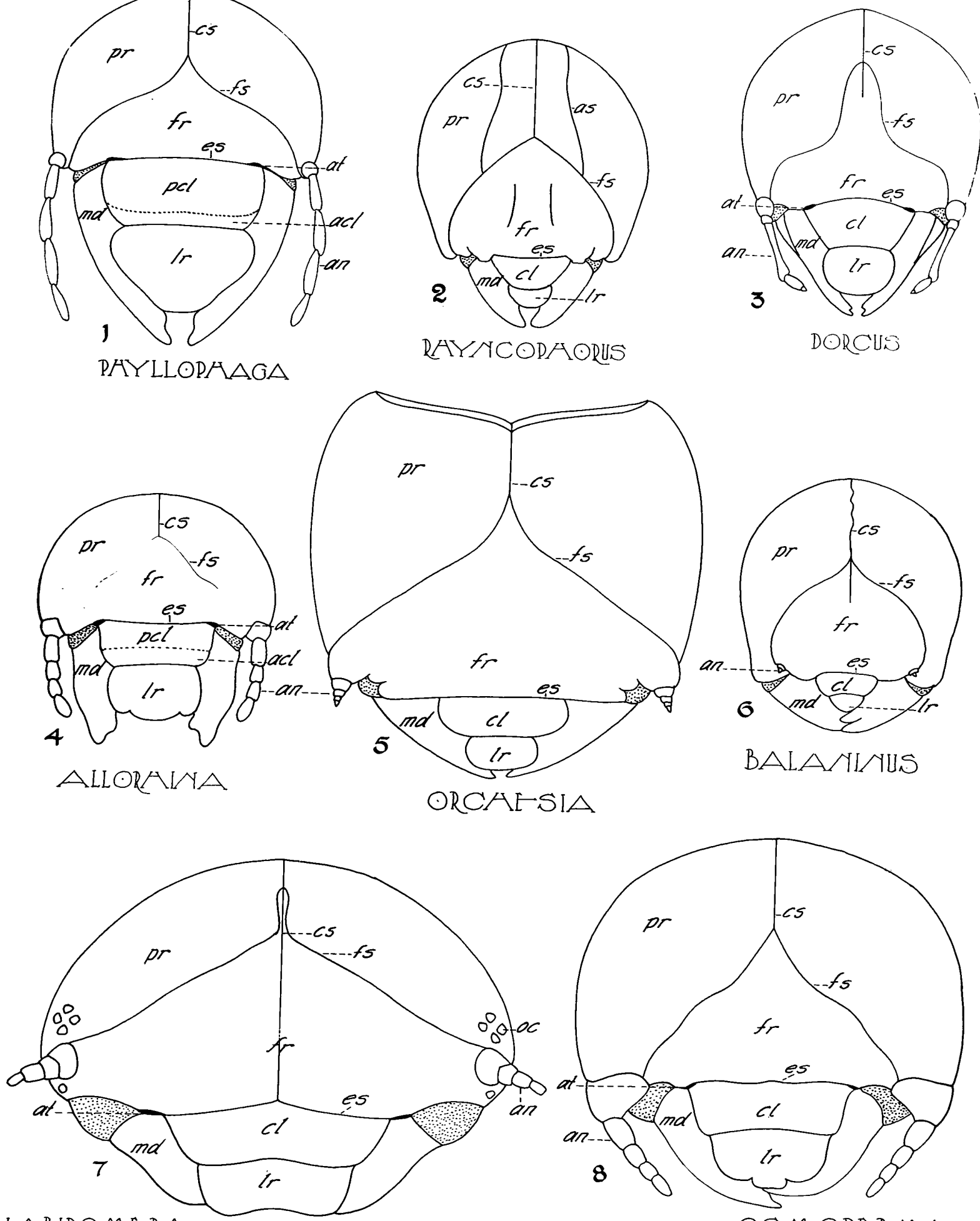

LABIDOMERA

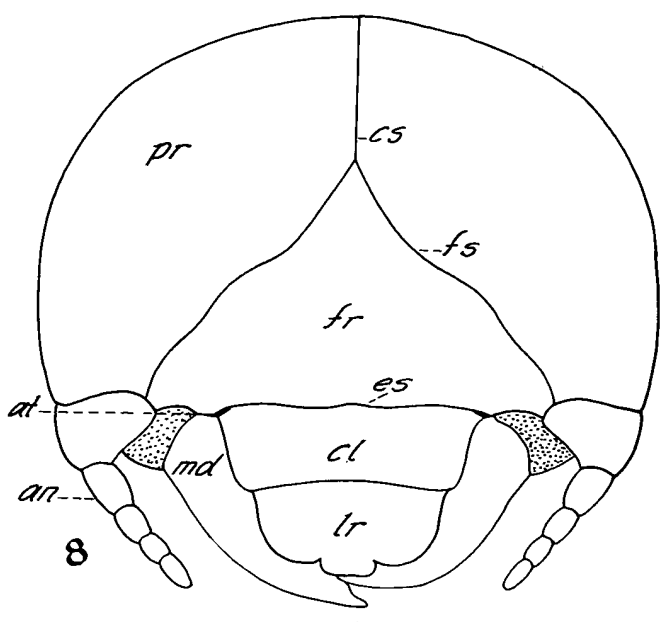

OSMODERMA 


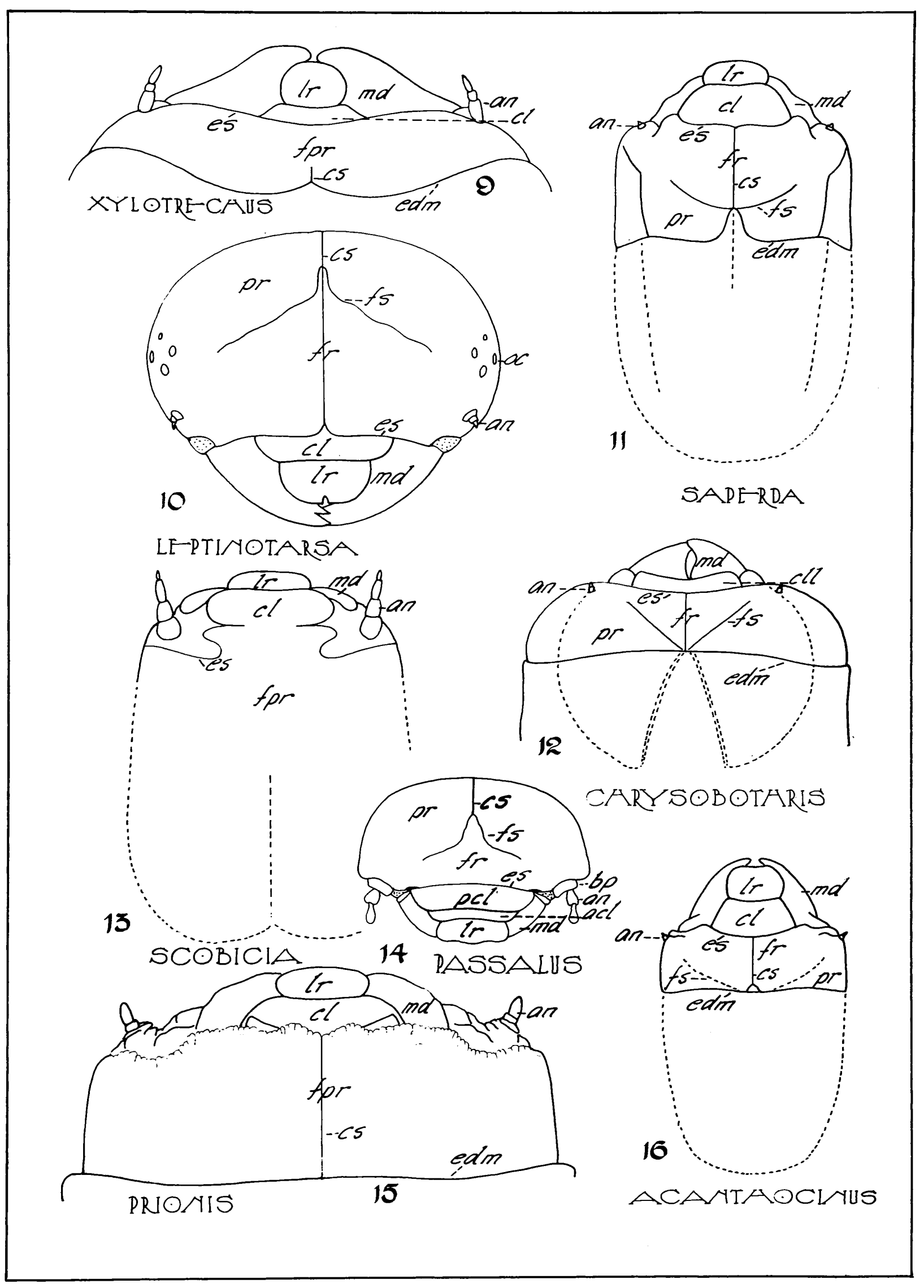




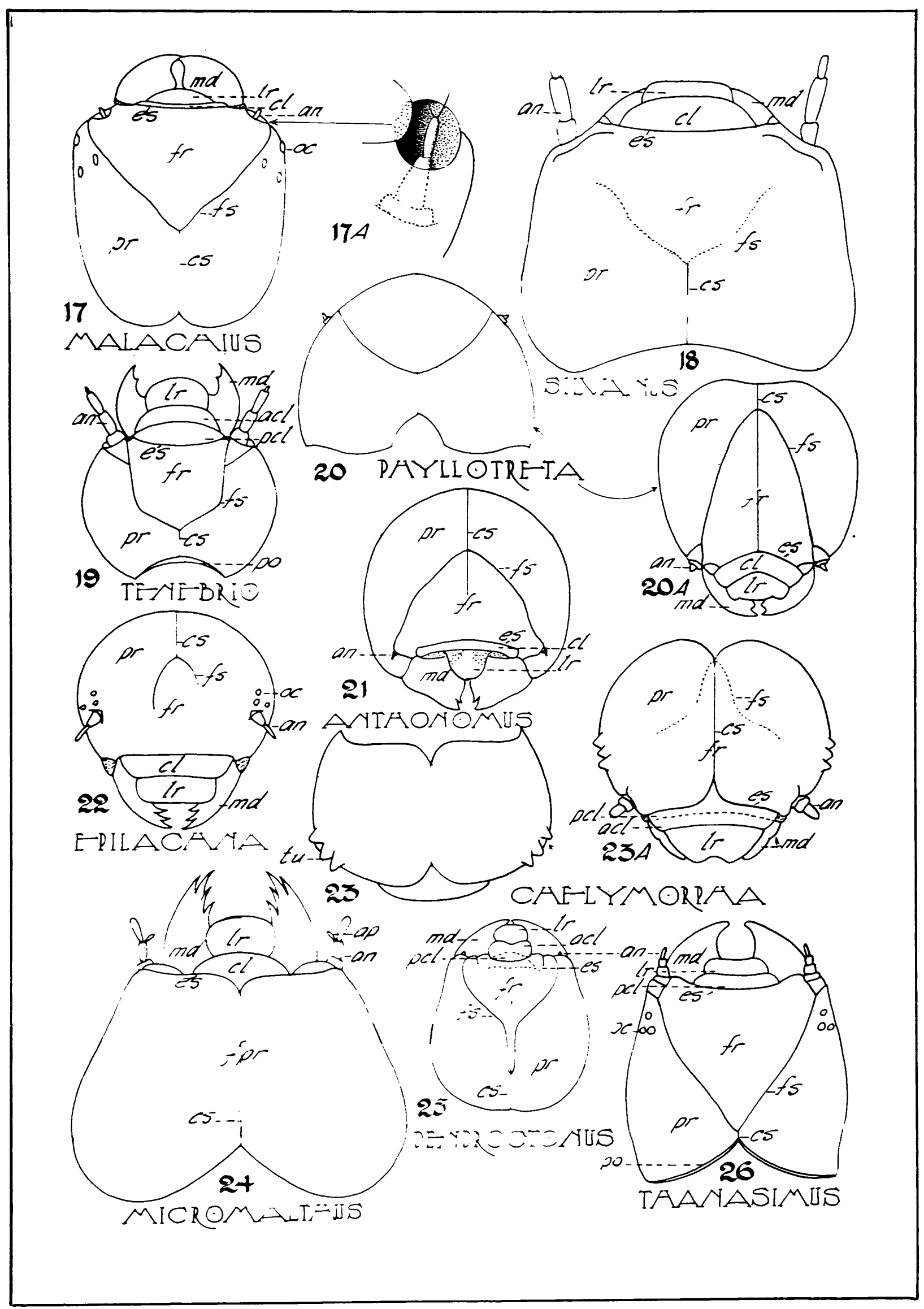


PIATE 4

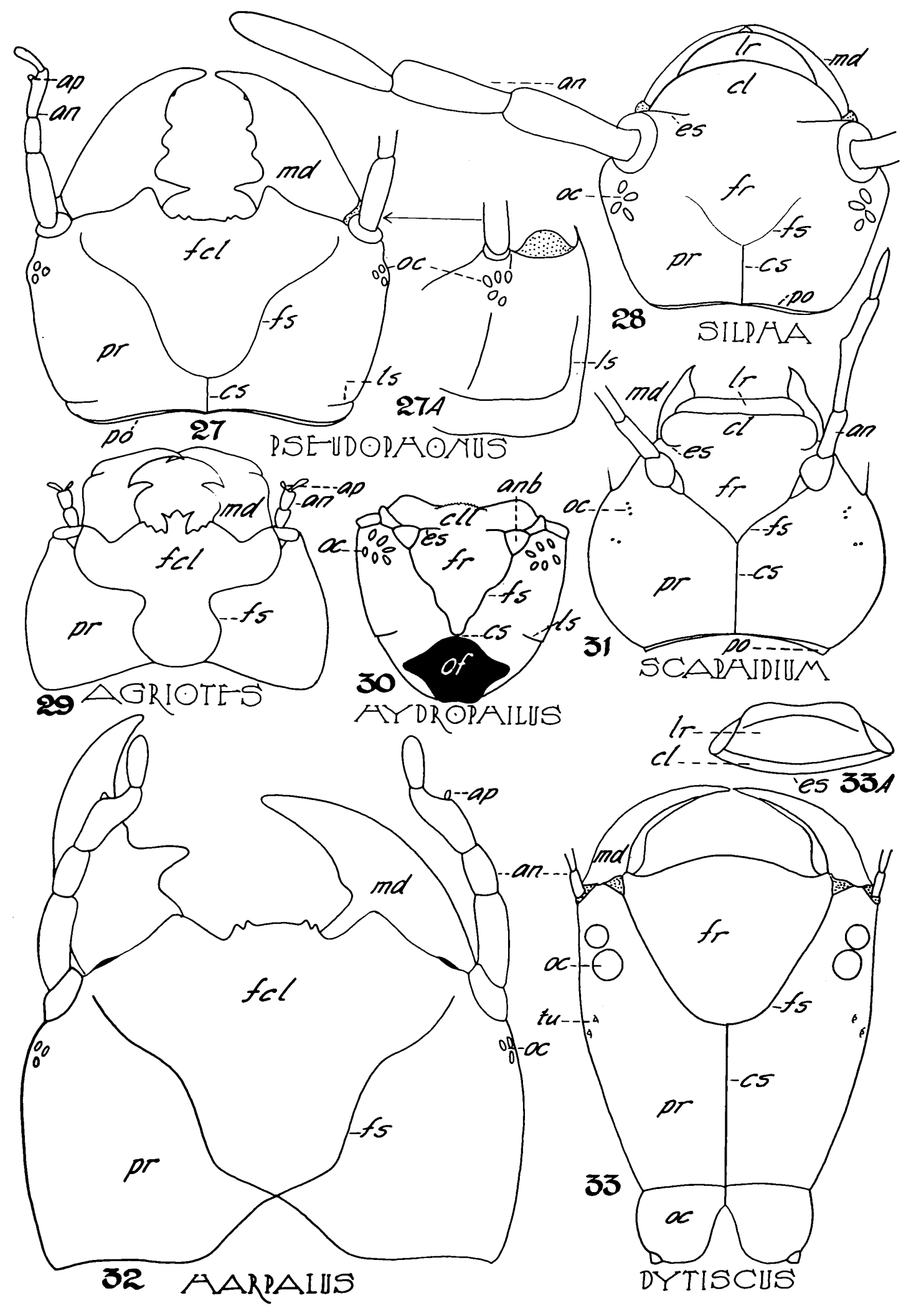



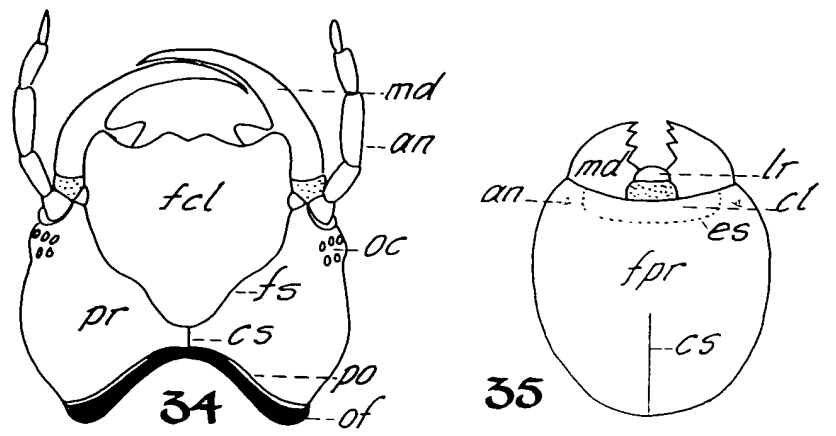

CARABUS

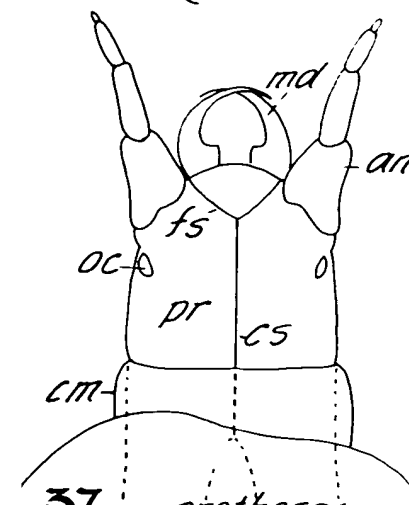

amisarines

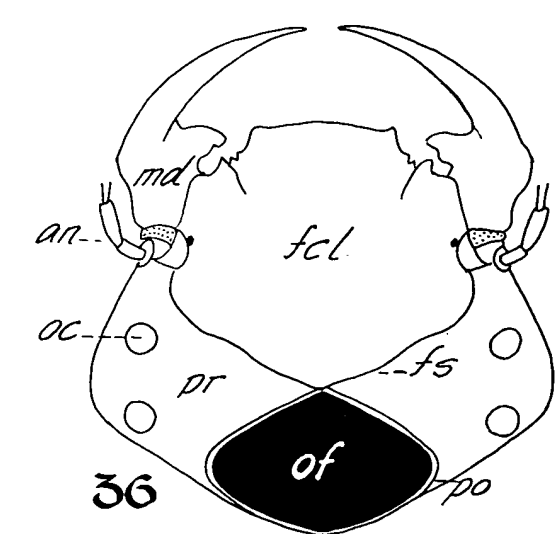

CICINDELA

37 prothorax
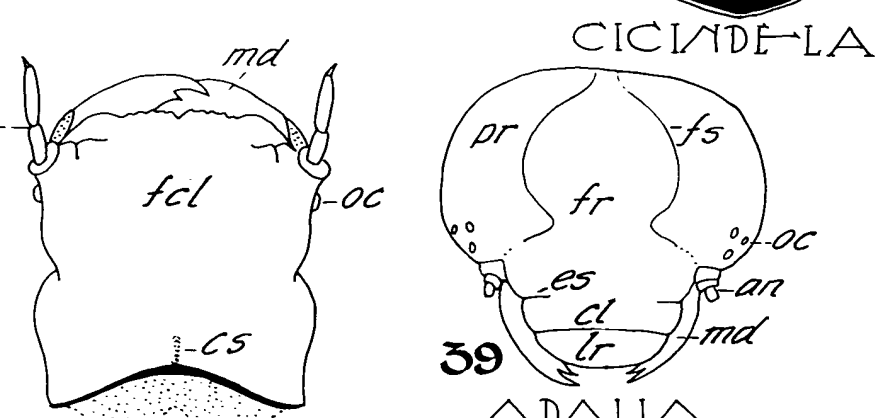

LAMPYRIS

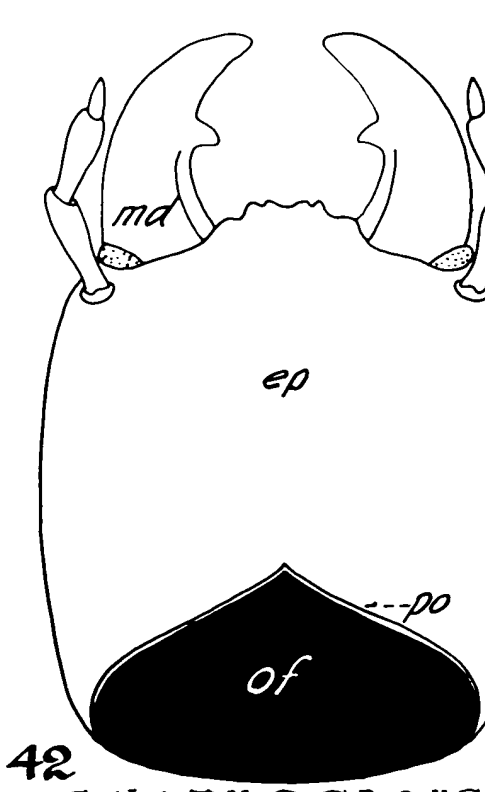

GNATAOCERUS
CAMTAARIS

i

ind an

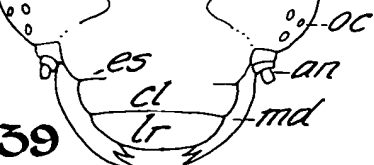

$\triangle D A L I A$

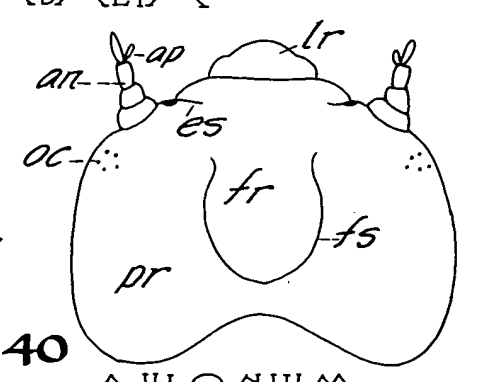

$\triangle U L O M I U M$

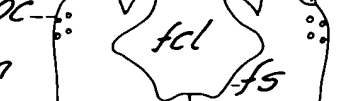

$y^{-a n}$

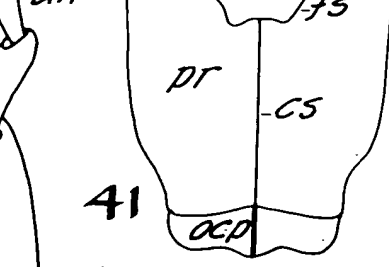

STAPAYLINUS

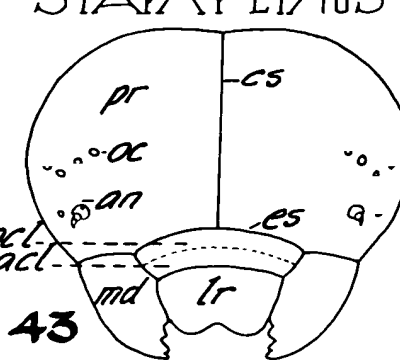

CASSIDA

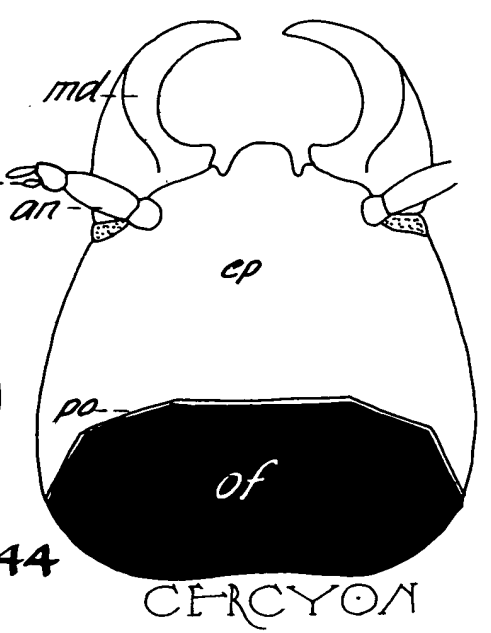




\section{PIATE 6}
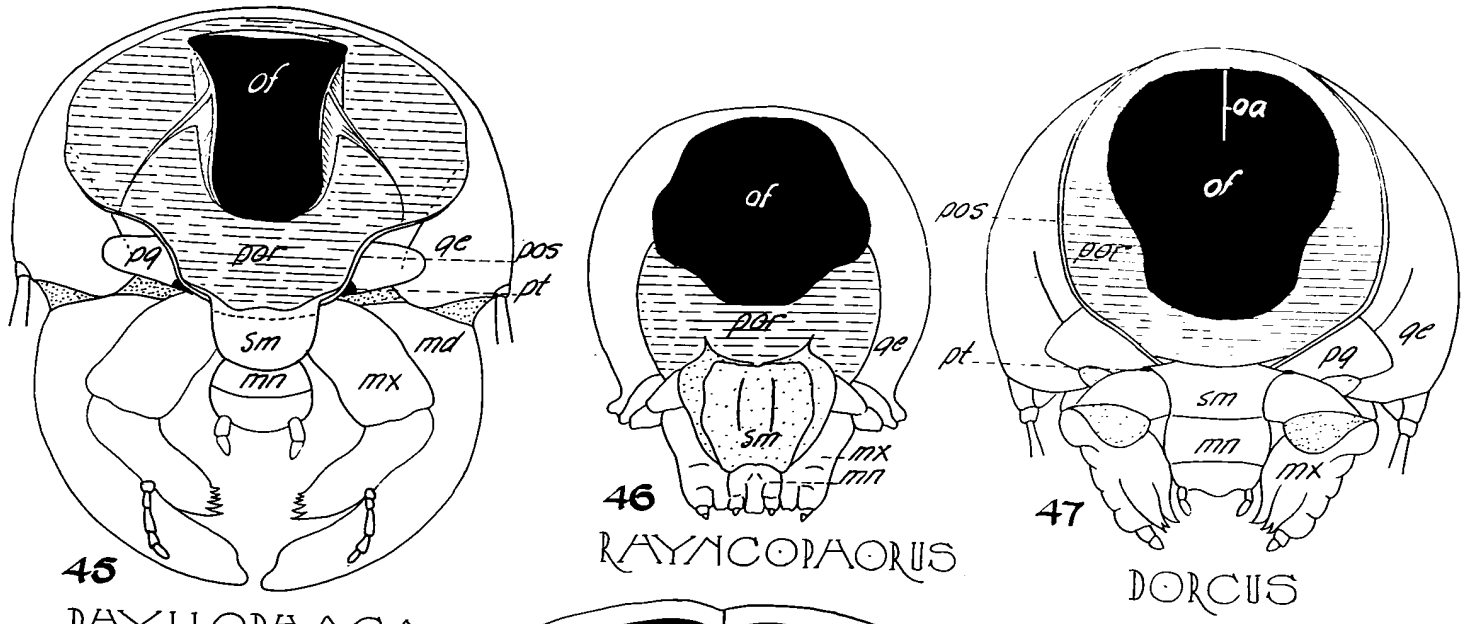

PAYLIODAAGA

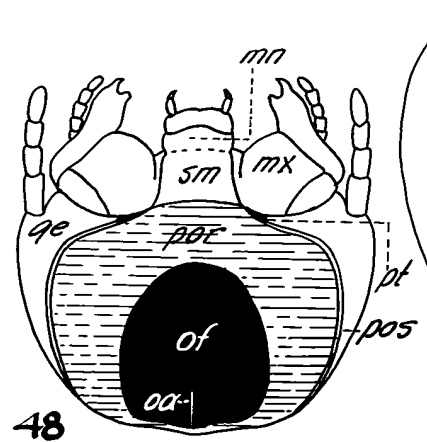

$\triangle L L O R A M A$

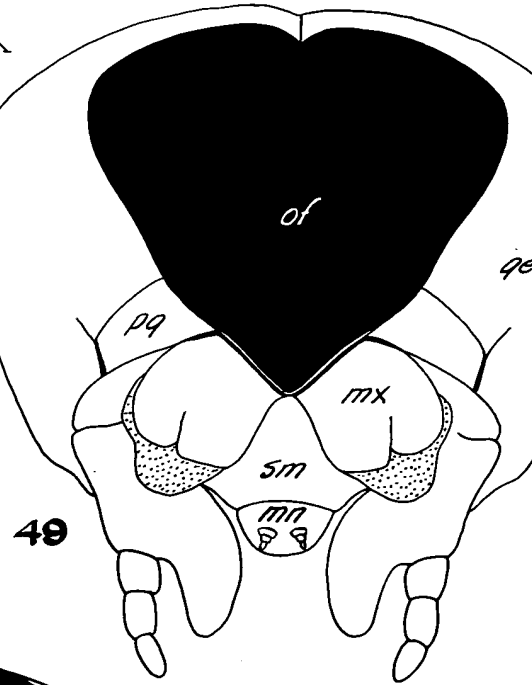

ORCAESLA

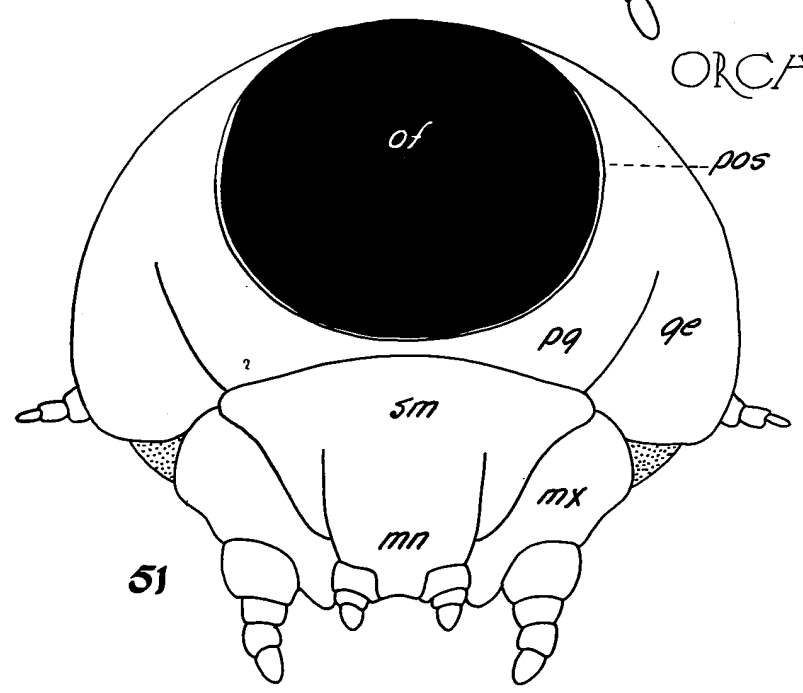

LABIDOMERA
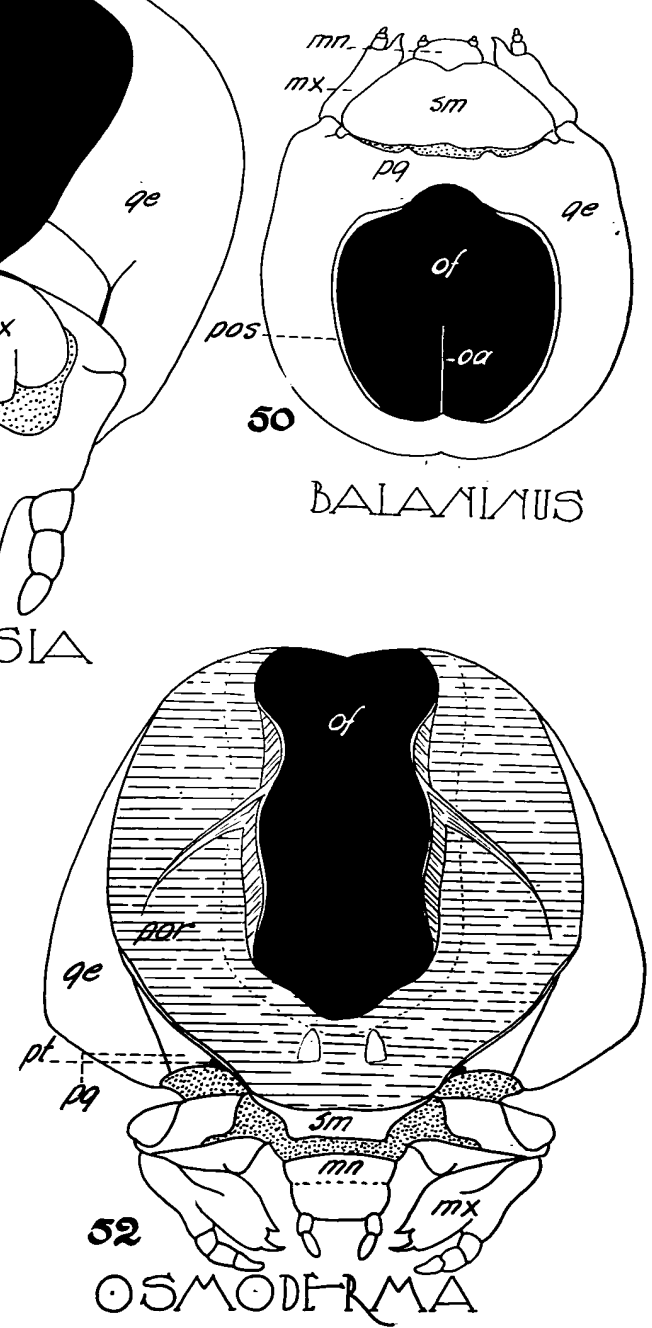

BALANINUS 


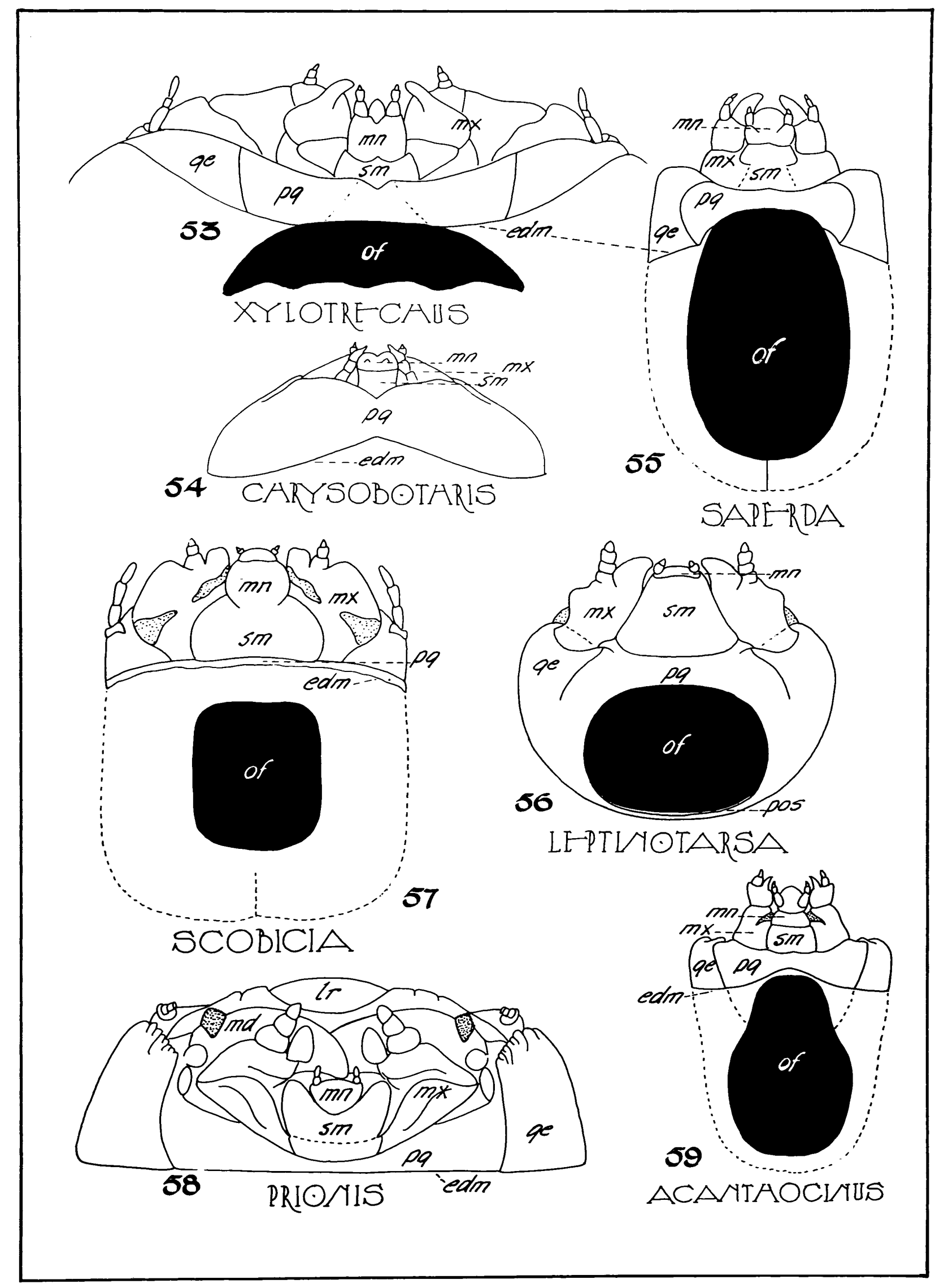


PIAIE 8

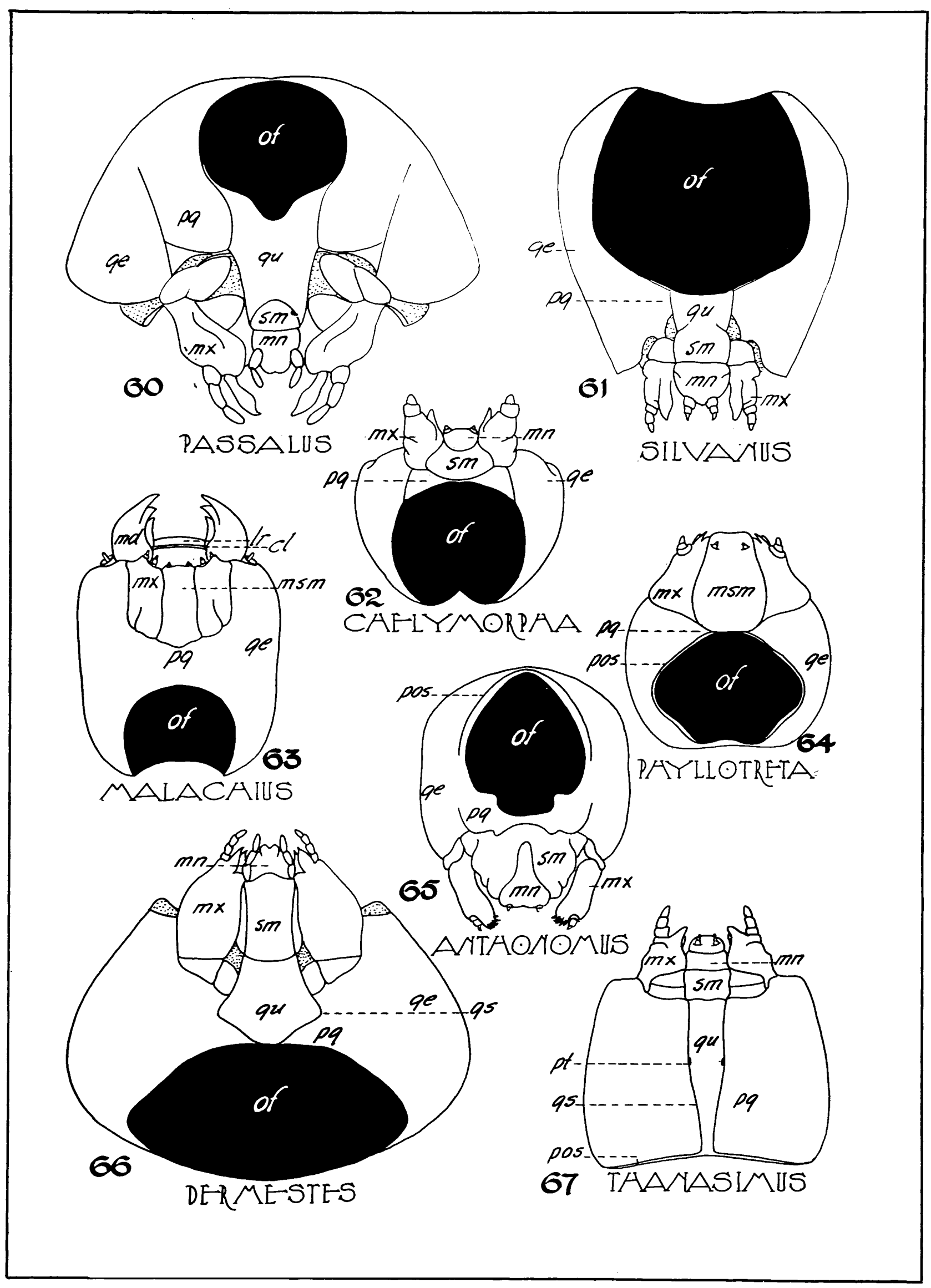




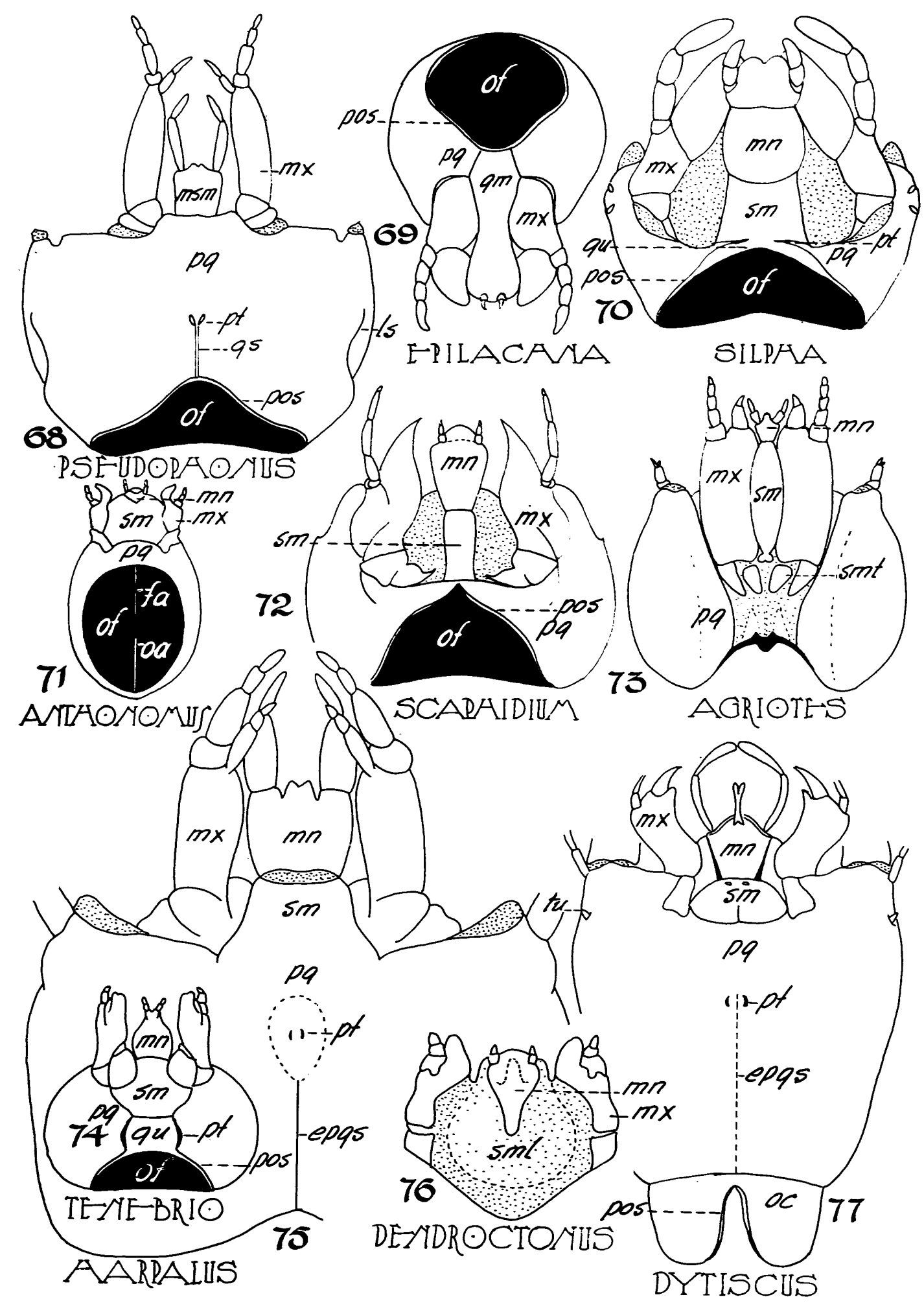




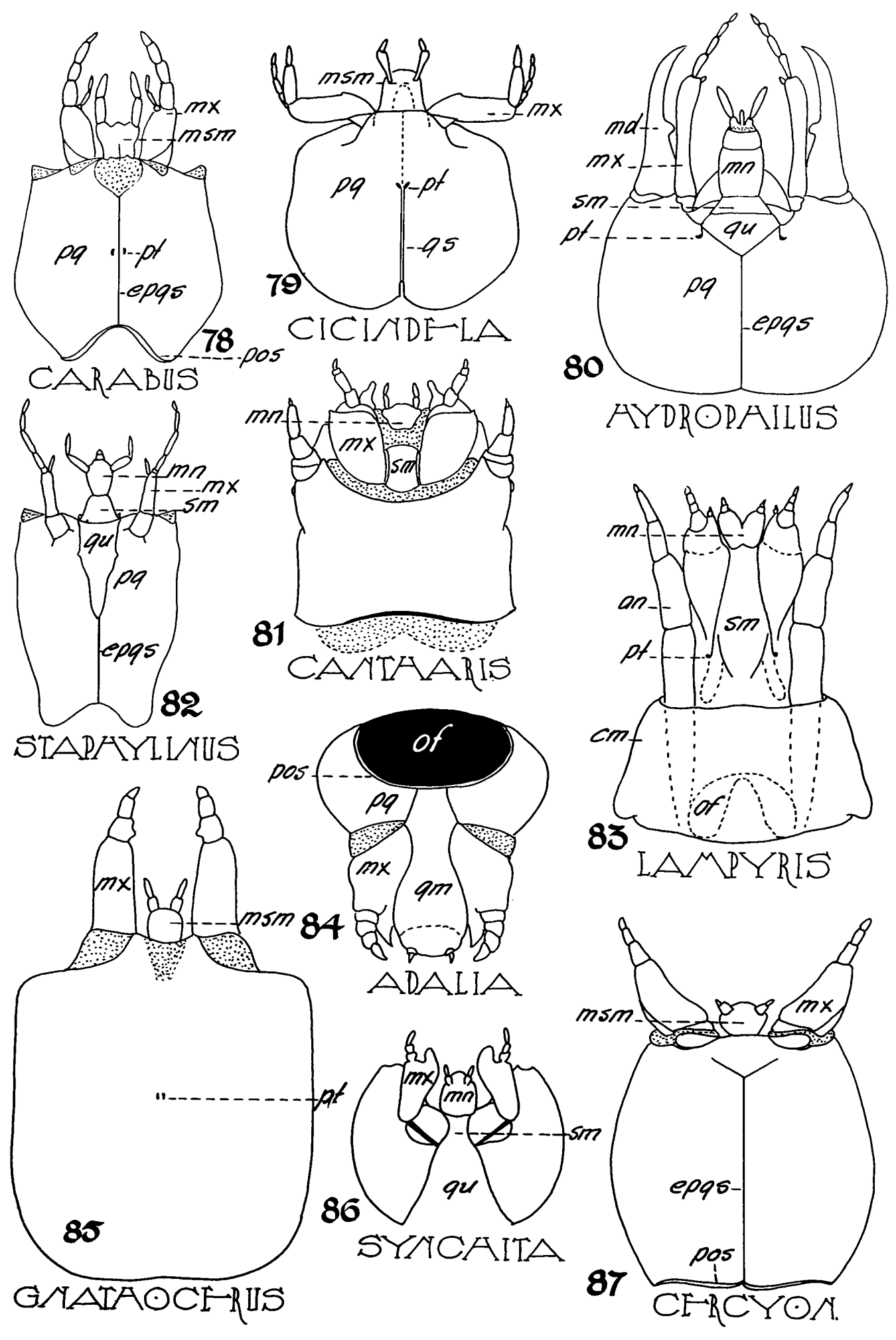



